\title{
Simulation for Fitting the Bending Shape of Fruit Branches of Lycium barbarum Based on the Finite Element Method
}

\author{
Yun Chen $\mathbb{D}^{\mathbb{D}}$, Jian Zhao $\mathbb{D}^{\mathbb{D}}$, Qingyu Chen and Jun Chen * \\ College of Mechanical and Electronic Engineering, Northwest A\&F University, Yangling 712100, China; \\ chenyun_jd@nwafu.edu.cn (Y.C.); 2017052634@nwsuaf.edu.cn (J.Z.); 1013137743@nwafu.edu.cn (Q.C.) \\ * Correspondence: chenjun_jdxy@nwsuaf.edu.cn; Tel.: +86-29-8709-1867
}

\begin{abstract}
The accurate modeling of wolfberry plant morphology is the basis for theoretical and simulation analyses of the wolfberry picking process. The curved shape of the fruit branches makes it challenging to model Lycium barbarum (wolfberry) plants. This paper establishes a threedimensional model of the branches under no gravity through field measurements, and then assesses the morphology of the branches under gravity load, fruit load, and branch load using finite element simulation. An orthogonal rotation combination experiment determined the relationship between branch morphology, length, growth angle, and growth mode parameters. The $p$-values of the prediction model were $0.0001,0.0067$, and 0.0203 , respectively. Finally, the bending shape of the actual branches was verified against the branches generated by the prediction model. The experimental results show that the prediction model accurately models the fruit-bearing branches of Lycium barbarum. This paper introduces a method to quickly predict the bending shape of fruit-bearing branches of Lycium barbarum, providing a theoretical basis for rapid modeling of the L. barbarum plant and a simulation analysis for its harvesting.
\end{abstract}

Citation: Chen, Y.; Zhao, J.; Chen, Q.; Chen, J. Simulation for Fitting the Bending Shape of Fruit Branches of Lycium barbarum Based on the Finite Element Method. Horticulturae 2021, 7, 434. https://doi.org/10.3390/ horticulturae7110434

Academic Editor: Arturo Alvino

Received: 29 September 2021

Accepted: 20 October 2021

Published: 25 October 2021

Publisher's Note: MDPI stays neutral with regard to jurisdictional claims in published maps and institutional affiliations.

Keywords: Lycium barbarum; fruit branches; FEM simulation; curve; prediction model

\section{Introduction}

The interaction mechanism between the Lycium barbarum plant and the picker is the basis for the research and development of the L. barbarum picker. The interaction between the Chinese wolfberry plant and the harvester is at the center of the research and development of all kinds of harvesting equipment. To determine the key operating parameters of $L$. barbarum fruit abscission, it is necessary to analyze the kinematics of the $L$. barbarum plant and the picking parts. Due to the irregular structure of plants, it is difficult to obtain analytical solutions by theoretical analysis. Numerical simulations analyze the motion and stress responses of different parts of plants under picking and have been widely used in the study of fruit abscission [1,2]. Therefore, an accurate three-dimensional plant model is a requirement of fruit abscission simulation analysis [3].

Since the 1960s, researchers have developed various methods to create three-dimensional models of vegetables, field crops, and trees [4,5]. These mainly include automata, Lsystems and particle systems, and image, data, and sketch reconstructions [6-14]. In 1968, the American biologist Aristid proposed the L-system [6,7]. In 1971, the Japanese scholar Honda created a computer simulation of the tree branch structure for the first time. In 1983, Reeves put forward the concept of a particle system [8-11]. In 1988, deReffye and the French Agricultural International Cooperation Research and Development Center (CIRAD) developed reference axis technology, known also as the automaton model [13,14]. The L-system, particle system, and automata create models according to the growth rules of plants. They are generally used to study the growth and development of plants, including their branching model, canopy distribution, and tendency. Image reconstruction is used to reconstruct the three-dimensional model of the plant by drawing on a single picture, multiple pictures, or videos with certain constraints [15]. Data reconstruction obtains the 
characteristic size or point cloud information of plants employing ground lidar, remote sensing, and three-dimensional scanning, and then divides different plants and organs using data segmentation to restore the three-dimensional shape of plants [16]. Image and data reconstruction create three-dimensional models of plants by using information obtained from natural plants. Both methods efficiently obtain a large amount of plant morphological information, but they are restricted by plant occlusion and data noise. Sketch reconstruction involves generating the corresponding three-dimensional plant model by drawing a sketch. One can flexibly modify the geometric size and topology of the plant on the mobile device to obtain realistic plant effects. This method can be used for the rapid implementation of various virtual scenes, such as games and gardens. L-system and automata are generally used to construct fruit harvesting and wind load response simulations and data reconstructions in combination with size measurements and constraints. In the fruit harvesting simulation process, different branch shapes and mechanical properties have significant differences in response to vibration, impact, and other picking actions. The bending shape of branches is one of the difficulties in plant modeling [17-22].

At present, there are three main methods used to construct the bending shape of branches. The first is to use the parameter curve to fit the measured data. This method obtains the approximate bending shape of branches, but the measurement workload is large, and the data are not universal [23]. The second method uses small vector segments to generate branches and model the bending of branches through the direction change of vector segments. The advantage of this method is that the bending direction of branches is very flexible; however, many parameters need to be given to control the bending of branches, and the direction of nonlinear change means that the branches are not smooth enough [24]. The third method uses the mechanical and finite element methods to determine the bending shape of branches through stress analysis, obtaining a more accurate branch shape $[25,26]$. The method of vector line segment may distort the shape of the whole branch because the direction vectors of each segment are set artificially. The method of parameter measurement and mechanical model calculation can obtain more realistic branches, but the measurement and model calculation work is large, the drawing period is long, and the measurement and calculation for specific branches lacks universality.

This paper aims to provide a fast and accurate modeling method for the bending shape of $L$. barbarum fruit branches. Firstly, the prediction model of branch shape is obtained by finite element analysis, and then the relationship between the parameters of the prediction model and branch length, growth angle, and planting mode is determined by a simulation test. Finally, the prediction model is verified with reference to real branches.

\section{Materials and Methods}

\subsection{Classification of Branches}

Figure 1 shows the branches of the Lycium barbarum at all levels, which was taken in Zhongning, Ningxia in August 2021. The Lycium barbarum in the picture is the main cultivated variety in Ningxia, the seven-year-aged Ningqi 7. The frame of the Lycium barbarum tree is composed of a trunk, primary branches, and secondary branches, with fruit-hanging branches growing on the primary branches and secondary branches. The trunk grows vertically. The primary and secondary branches are thick and grow along the initial growth direction, and the drooping deformation is small under the load of the lower branches and leaves. The fruit-bearing branches are slender and soft, and experience significant deformation under the load of fruit and leaves. Understanding this deformation is the research object of this paper. 


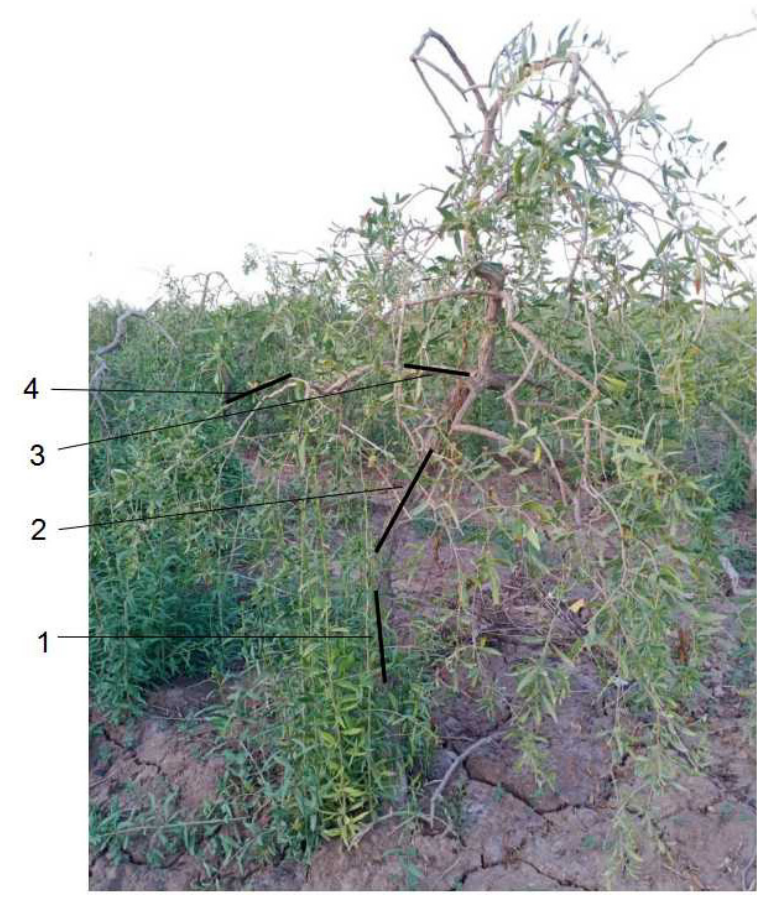

Figure 1. Structure and composition of the Lycium barbarum branches: (1) main branch; (2) primary branches; (3) secondary branches; (4) fruit branches.

L. barbarum fruit branches can be divided into independent branches without embranchment and compound branches with embranchment. These two types of branches grow on the vertical and horizontal planes, respectively. They can therefore be subdivided into four types of branches, named type I, type II, type III, and type IV. As shown in Figure 2 (by the red lines), type I and type III branches have no embranchments, type II branches have embranchments, and their superior branches grow along the vertical plane; type IV branches have embranchments, and their superior branches grow in the horizontal direction (approximately).

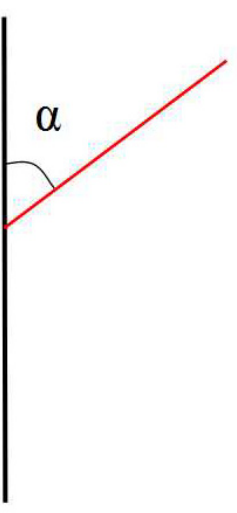

(a)

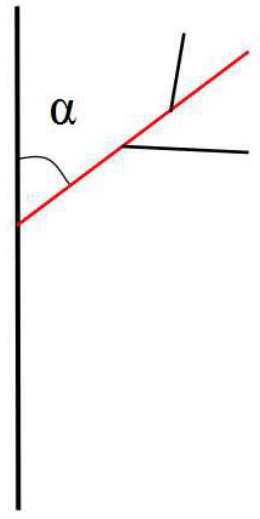

(b)

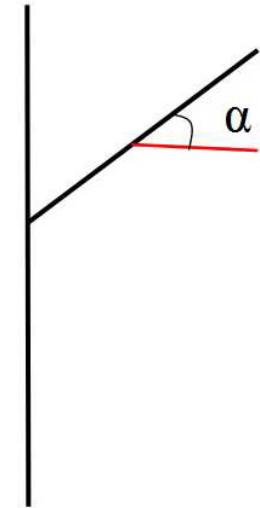

(c)

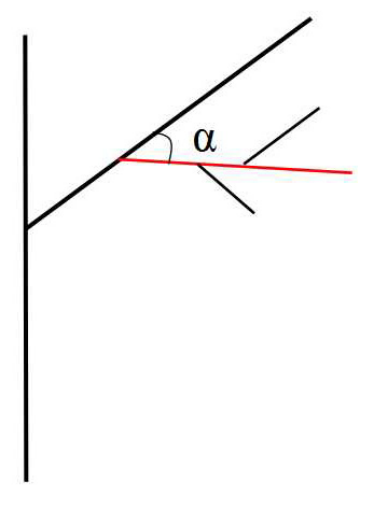

(d)

Figure 2. Four branch types: (a) type I, upper branches in the vertical plane, with no lower branches; (b) type II, upper branches in the vertical plane, with lower branches; (c) type III, superior branches in the (approximately) horizontal plane, with no lower branches; (d) type IV, superior branches in the (approximately) horizontal plane, with lower branches. 


\subsection{Parameters Measurement}

When a large number of Lycium barbarum matured in June, three Lycium barbarum trees with well-developed crowns were selected, and the length, base diameter, top diameter, and growth angle of fruiting branches were measured. June is still the peak period for the growth of fruit branches, and fruit branches can grow about $10 \mathrm{~mm}$ every day. In order to ensure the reliability of branch size distribution, the data of three Lycium barbarum plants were measured in 2 days. The number of fruiting branches, the number of nodes on the fruiting branches, and the number of leaves and fruits growing on the nodes were counted, while the quality of ripe fruit, green fruit, flowers, leaves, and fruit stalks was also measured.

\subsubsection{Length of Branches}

The fruiting branches of the Lycium barbarum can be divided into current fruiting branches and biennial fruiting branches. The fruiting branches of the same year develop and grow in spring and autumn, and the length of the fruiting branches which germinated this spring was close to $400 \mathrm{~mm}$ when the fruit matured in the middle of June, and the length of the fruiting branches which germinated in August was about $300 \mathrm{~mm}$ when the autumn fruit was harvested in the middle of September. The length of some biennial branches with a large fruiting capacity can reach $800 \mathrm{~mm}$, while the length of other biennial fruiting branches can be kept between $300 \mathrm{~mm}-500 \mathrm{~mm}$ by pruning.

\subsubsection{Base Circle and Top Circle of Branches}

The base diameter of the branch refers to the diameter at the beginning of the branch, and the top diameter refers to the diameter at the end of the branch. With the increase in the age of the Lycium barbarum, the annual growth of the branch diameter decreases year by year. Annual growth is further affected by precipitation, fertilization, and other factors [27]. There was little difference between the top diameter and the base diameter of the current-year-bearing branches that were measured for this study, but there was a large difference between the base diameter and the top diameter of the biennial branches due to repeated pruning and growth.

\subsection{Fruits and Leaves on Fruiting Branches}

Every $5 \mathrm{~cm}$ on the fruiting branch, there is a node where leaves grow. Ripe fruit, unripe fruit, and flowers will grow at the nodes during the full production stage. The quality of fruits and leaves growing on different lengths of fruit branches is different, which makes the bending shape of fruit branches very different [28]. We randomly selected 100 branch nodes, and counted the growth numbers of leaves, ripe fruits, unripe fruits, and flowers on each node.

\subsection{Simulation Models}

\subsubsection{Geometric Model and Mesh Generation}

The schematic diagram of the wolfberry tree without gravity is shown in Figure 3a. In a separate geometric model, part of the trunk and hanging fruit branches were cut off to reduce the amount of calculation and facilitate simulation analysis. A geometric model of a fruiting branch without gravity was created in Solidworks 2013 (Dassault Systems Simulia Corp., Concord, MA, USA). Four parameters were used to create the three-dimensional branches model: branch length, base circle diameter, circle diameter, and growth angle. The median length of the fruit-bearing branch was $550 \mathrm{~mm}$, and the diameter of the base and top circles were determined using Formula (1). The branch growth angle was taken as $60^{\circ}$, and the three-dimensional model of the branch under no gravity was obtained, as shown in Figure 3b. The file was imported into Ansys Workbench 18.1 (ANSYS, Inc., Pittsburgh, PA, USA), which discretizes the 3D model through meshing, and creates the finite element model of branches. Because the branches have cylindrical structures, to better adapt to the arc of the cylinder, the tetrahedral mesh was used to divide the branches. In order to 
give consideration to calculation accuracy and efficiency, the mesh size of the branch was set at $5 \mathrm{~mm}$, and the mesh size was set at $1 \mathrm{~mm}$ at the junction of branches and supports and at the junction of branch and fruits, as shown in Figure 3c. The model contains 16,458 elements and 33,366 nodes.

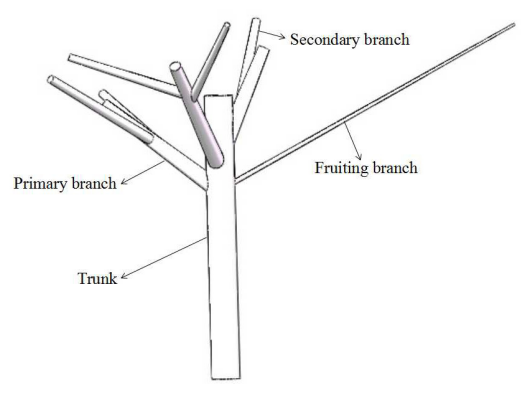

(a)

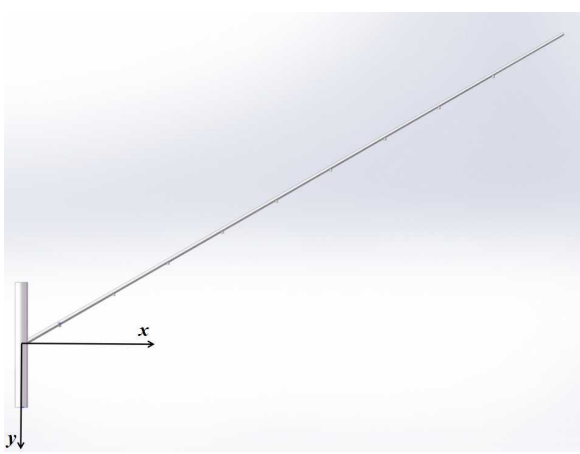

(b)

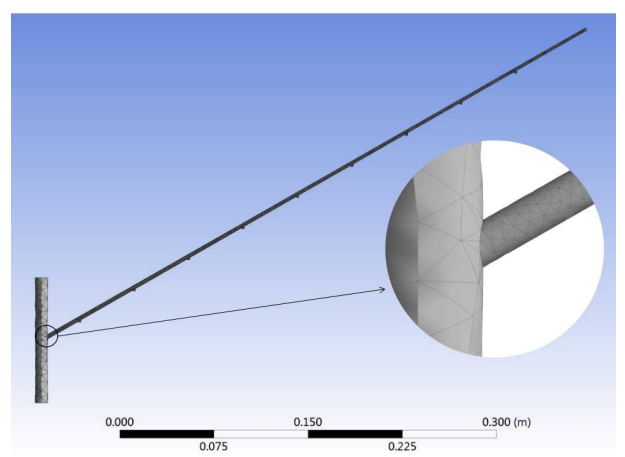

(c)

Figure 3. Three-dimensional model and finite element model of branches: (a) schematic diagram of wolfberry tree without gravity; (b) branch geometric model; (c) branch meshing and local mesh refinement.

\subsubsection{Simulation Parameters}

The parameters used in the finite element model of the branches include material density, elastic modulus, and Poisson's ratio. The density of the material was measured using the drainage method (Standard: ASTMD854-10). In the measurement, the hanging fruit branches of the Lycium barbarum were cut into small segments that were $20 \mathrm{~mm}$ long, and five segments were selected from the beginning to the end of the branches. Toluene solution was used as the measuring liquid in order to reduce volume measurement error [1]. We placed $50 \mathrm{~mL}$ of toluene solution into a $100 \mathrm{~mL}$ measuring cylinder (type: 1601; measurement range: $0-100 \mathrm{~mL}$; precision: $1 \mathrm{~mL}$; manufactured by Tianjin Glass Instrument Factory, Tianjin, China) and dipped the sample into the toluene solution to obtain the volume. An electronic balance (type: Professional digital jewelry scale 8028series; measurement range: 0-100 g; precision: $0.001 \mathrm{~g}$; manufactured by Shenzhen Diheng Electronics Co., Ltd., Shenzhen, China) was used to measure the change in mass before and after the branch was put in, and the mass difference was calculated to obtain the mass of the branch. The ratio of mass to volume was calculated to obtain the branch density. The elastic modulus of fruit-bearing branches was determined by the stress-strain method [1]. The formula for calculating the elastic modulus of the branch is as follows:

$$
E=\frac{F l}{A l_{0}}
$$

$E$ is the elastic modulus of the branch in the formula. $A$ is the cross-sectional area of the branch. The diameter of the sample is measured using a Vernier caliper and calculated using the area formula of the circle. $l$ is the length of the branch sample, which is measured using a Vernier caliper. $F$ is the magnitude of the external force acting on the branch, and $l_{0}$ is the change in the length of the branch under the force $F$, which is obtained using the loading test of the universal testing machine. By substituting each piece of data into the formula, the elastic modulus of the hanging fruit branch can be calculated as shown in Table 1. Zhang Zui measured the elastic modulus of branches in the range of 420.96-749.28 MPa by using the similar method in [29]. The average elastic modulus of all branches of Lycium barbarum given in [30] is $665 \mathrm{MPa}$. This shows that the calculation results of the elastic modulus in this study are reasonable. 
Table 1. Simulation parameters.

\begin{tabular}{cccc}
\hline & Density $\boldsymbol{\rho} / \mathbf{k g} \cdot \mathbf{m}^{-3}$ & $\begin{array}{c}\text { Elastic Modulus } \\
\text { E/MPa }\end{array}$ & Poisson Ratio v \\
\hline Fruiting branches & 421 & 585 & 0.3 \\
\hline
\end{tabular}

The Poisson's ratio for wolfberry branches has been measured or used by many people. $\mathrm{Hu}$ Mingming set the Poisson's ratio of goji berry branches at 0.3 during his modal analysis of goji berry plants in 2018 [30]. The average Poisson's ratio of branches determined by Zhang Zui in 2016 was 0.327 [29]. When He Miao studied the dynamics of Lycium barbarum plants in 2018, she set the Poisson's ratio of Lycium barbarum branches at 0.3 in the simulation calculation [31]. In 2021, Zhao Jian conducted a simulation test of wolfberry fruits falling off by force, and the Poisson's ratio of hanging fruit branches was 0.3 [1]. Therefore, Poisson's ratio of branches of the Lycium barbarum was assumed to be 0.3 as shown in Table 1.

\subsubsection{Physical Model}

L. barbarum branches are subject to gravity and the tensile force of fruit and leaves at the nodes. According to the growth and force directions of branches, branches are mainly subject to shear force and therefore belong to the beam element. The most common threedimensional beam element models used in ANSYS static analysis are the beam 4 constant section and beam 187 variable section beams. The diameter of the L. barbarum branches decreases from the base circle to the top circle, meaning they should be categorized as variable section beams. Therefore, the beam 187 variable section beam element is selected. The whole branch is regarded as a Euler beam, with six degrees of freedom per solving element, i.e., three linear degrees of freedom and three rotational degrees of freedom. The deflection curve differential equation of Euler beam under load [32] is:

$$
\frac{\mathrm{y}^{\prime \prime}}{\left[1+\left(\mathrm{y}^{\prime}\right)^{2}\right]^{\frac{3}{2}}}=-\frac{M(x)}{E I}
$$

In this formula, EI is the bending stiffness and $M(x)$ is the bending moment at the section. This is a nonlinear equation, and the exact solution is challenging to obtain. Many scholars have simplified this formula for different applications and to improve its practicability [32]. However, the obtained differential equations are still challenging to apply to the direct calculation results to drive the three-dimensional modeling of branches. In this study, the finite element solution was used to obtain the deformation shape of branches.

\subsubsection{Constraints and Loads}

The root of the superior branch of the fruit-hanging branch is subject to fixed constraints, and the superior branch plays a supporting role with the fruiting branch. The load on the branch includes its gravity, the tension caused by the gravity of the fruit and leaves at each node, and the pressure of the lower branches. The gravity of the branch itself is applied by inertial load, and it can be calculated according to Formula (3):

$$
G_{1}=\rho V g=\frac{1}{12} \rho g \pi l\left(D^{2}+d^{2}+D d\right)
$$

where $G_{1}$ is the branch gravity, $\rho$ is the branch density, and $g$ is the gravitational acceleration. Using the circular platform volume formula and Formula (1), the relationship between the gravity of the branch itself and the branch length can be obtained as follows:

$$
G_{1}=\frac{1}{12} \rho g \pi\left(1.2 * 10^{-5} * l^{3}+0.0224 l^{2}+11.2 l\right)
$$


The maximum ratio of the number of flowers to the number of Chinese wolfberry fruits could be calculated in the first ten days of June. At this time, the root fruit of the branch is the first to mature, while the fruit that matures at the beginning of July is in a state of flowering, and the ratio of flowers to fruit is close to one. Considering that there are two ripe fruits, four green fruits, six flowers and three leaves on the node, it is calculated that the flower mass accounts for $6.7 \%$ of the node mass, and that this ratio decreases rapidly with the increase in the number of mature fruits. Therefore, the flower quality is ignored in the simulation. The number and quality of growing leaves, mature fruits, and immature fruits at each node were averaged to determine the concentrated mass force applied on each node as follows:

$$
G_{2}=n_{1} m_{1}+n_{2} m_{2}+\left(n_{1}+n_{2}\right) m_{3}
$$

where $G_{2}$ is the equivalent tension at the node, $n_{1}$ is the number of ripe fruits at the node, $n_{2}$ is the number of unripe fruits at the node, $m_{1}$ is the mass of ripe fruits, $m_{2}$ is the mass of unripe fruits, and $m_{3}$ is the mass of the fruit stalk. If the fruit-hanging branch has lower branches at the node, the force of the branches on the fruiting branch was applied in the same way as the inertial load, and the load was calculated by Formula (3). Figure 4 shows the constraint and load application positions. In the figure, A is the fixed constraint, and the rest represent at each stage the concentrated mass force applied at the respective node.

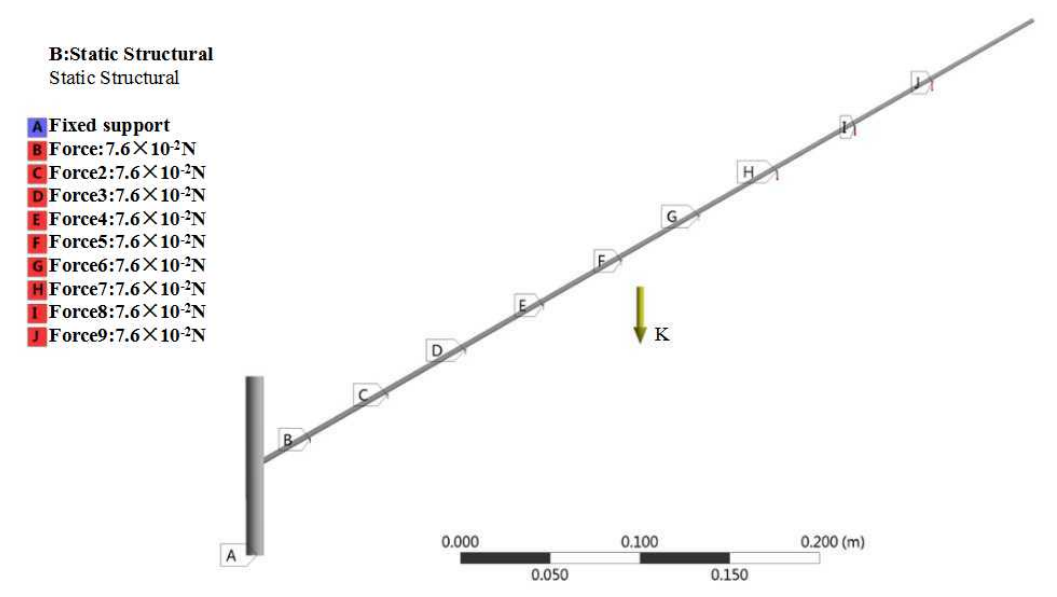

Figure 4. Constraints and loads of finite element models. A is the fixed constraint; B-J represent where the load generated by the leaf and fruit is applied at each node, which is calculated in the form of concentrated mass force; $\mathrm{K}$ is the load generated by the branch's own gravity, applied as an inertial load.

\subsection{Sequential Loading Test}

In the experiment, the weight was loaded according to fruit maturity at each stage of the branch to simulate the bending process of the branch in its natural state. Therefore, a total of five loads were performed. First, only the gravity of the branch was loaded, that is, the inertial load marked by $\mathrm{K}$ in Figure 4 . Second, based on the $\mathrm{K}$ load, three concentrated mass forces were applied on nodes B, C, and D, at the root of the branch. E, F, and G loads were then applied. The third load was based on the above loads. The fourth load continued to increase the three concentrated mass forces of H, I, and J. For the fifth load, the branch load was increased at C, E, and G.

Before solving, 'path' was added in WORKBENCH to the branch centerline to obtain the coordinate values of the branch centerline before and after deformation to determine the branch shape curve.

\subsection{Orthogonal Simulation Test}

Through intuitive understanding, it can be found that the overall shape of fruithanging branches is a part of quadratic or higher-order curves. Determining the parameters 
describing the curve, that is, the coefficients of polynomial items, is the key to accurately describing the shape of the branches. It was assumed that the highest order term of the polynomial describing the shape of fruit-bearing branches is less than cubic; that is, the prediction polynomial coefficient of the shape curve is $3-4$, and the expression of the shape curve is assumed as follows:

$$
y=a_{1} x^{3}+a_{2} x^{2}+a_{3} x+a_{4}
$$

where, $x$ and $y$ are the horizontal and vertical coordinates of each point on the centerline of the branch under the branch coordinate system, defined in Figure 3a. The branch coordinate system takes the center of the base circle of the branch as the coordinate origin, parallel to the ground and along the branch direction as the positive direction of the $x$-axis, and downward perpendicular to the ground as the positive direction of the $y$-axis. The coefficients of the morphological curve are $a_{1}, a_{2}, \mathrm{a}_{3}$, and $a_{4}\left(a_{1}\right.$ might be 0$)$. They are all functions that have branch length, growth angle, and implantation position as independent variables.

To investigate the relationship between branch length, growth angle, planting position, and each coefficient, three-factor and three-level orthogonal simulation experiments were carried out. The levels of branch length (A) and growth angle (B) are determined to be 300 $\mathrm{mm}, 550 \mathrm{~mm}$, and $800 \mathrm{~mm}$, and $40^{\circ}, 60^{\circ}$, and $80^{\circ}$, respectively, according to the measured size distribution. The fruit-bearing branch attachment position (C) codes are 1, 2, 3, and 4 . The Box-Behnken method of orthogonal tests establishes the efficiency and effectiveness of the test. Table 2 shows the tests arrangement.

Table 2. Orthogonal test arrangement.

\begin{tabular}{cccc}
\hline Test No. & $\begin{array}{c}\text { Factor A } \\
\text { Length/mm }\end{array}$ & $\begin{array}{c}\text { Factor B } \\
\text { Growth Angle/ }\end{array}$ & $\begin{array}{c}\text { Factor C } \\
\text { Growth Location }\end{array}$ \\
\hline 1 & 300 & 60 & 4 \\
2 & 550 & 60 & 2 \\
3 & 550 & 80 & 4 \\
4 & 550 & 40 & 4 \\
5 & 800 & 60 & 4 \\
6 & 300 & 40 & 2 \\
7 & 550 & 40 & 1 \\
8 & 550 & 80 & 1 \\
9 & 300 & 60 & 1 \\
10 & 800 & 60 & 2 \\
11 & 550 & 60 & 3 \\
12 & 800 & 80 & 3 \\
13 & 550 & 60 & 3 \\
15 & 550 & 60 & 3 \\
16 & 300 & 80 & 3 \\
\hline
\end{tabular}

\subsection{Comparison and Verification between Branch Shape Prediction Curve and Real Curve}

Because the branches are soft, shaking, and sheltered from each other in the full productive stage, it is difficult to ensure the accuracy of the abscissa and ordinate of each point of the branches by directly measuring the real branch shape. Therefore, the image recognition method described in reference [33] was used to determine the coordinates of each point on the branch centerline. The length, growth angle, and growth position of branches were measures using field pictures. Branch edges and non-target areas were manually identified. The true-color image was transformed into a gray image in Matlab R2010a (MathWorks.Inc., Natick, MA, USA), and the gray image was transformed into a binary image using fixed threshold segmentation. The find function was used to derive the coordinates of non-zero pixel values of the picture, that is, the coordinate values of all 
pixels on the branch. The pixel coordinates of each point were transformed into length coordinates using the image scale, and then the coordinates were transformed from the picture coordinate system into the branch coordinate system to obtain the horizontal and vertical coordinates of 50 equidistant points on the branch centerline.

The length, growth angle, and growth position serial number of the above branches were brought into the morphological prediction curve equations to obtain the prediction curve equation results. Fifty abscissae equidistant in the $x$ direction and were brought into the prediction curve to obtain the coordinate values of 50 points on the prediction curve.

The abscissa and ordinate values of 50 equidistant points on the centerline of the real branch were compared with the abscissa and ordinate values of the 50 points on the shape prediction curve, and the deviation was used to evaluate the accuracy of the prediction curve.

\section{Results}

\subsection{Measurement Results of Fruit Branch Parameters}

Figure 5 shows the length distribution of hanging fruit branches, from which it can be seen that $90 \%$ of the hanging fruit branches are distributed between 330 and $760 \mathrm{~mm}$. SPSS 22.0 (International Business Machines Corporation, Armonk, New York, NY, USA) was used to conduct a Shapiro-Wilk (S-W) test on the measured results, and the $p$-value of S-W test was $0.765(>0.05)$. It can be seen that the length distribution of branches meets normal distribution.

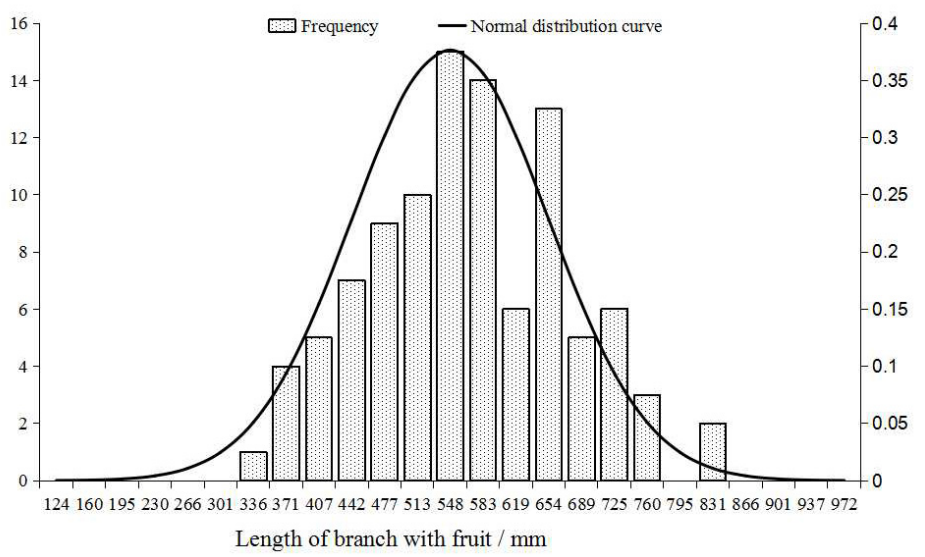

Figure 5. Length distribution of fruiting branches.

The measured data show that the top diameter of the fruiting branches is $47.06 \%$ to $61.76 \%$ of the base diameter. Figure 6 shows the size distribution of the base and top diameters of fruit branches.

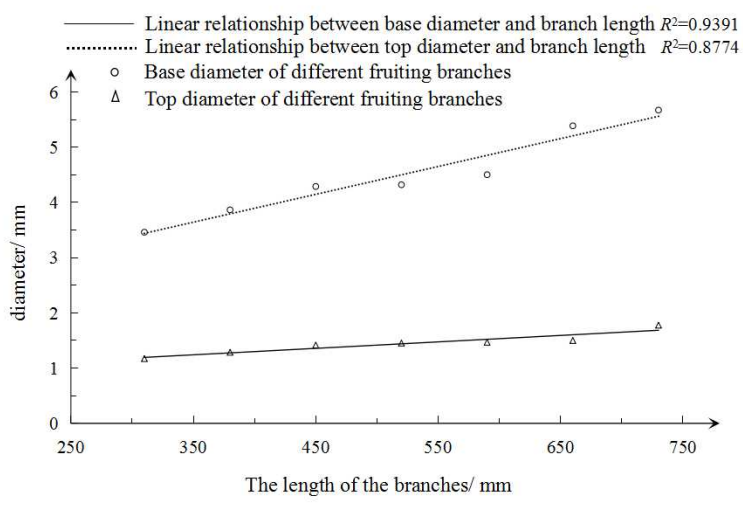

Figure 6. Relationship between branch base circle diameter and branch length. 
The linear relationship between base diameter and branch length is obtained using the least-squares fitting technique. It can be seen from Figure 6 that with the increase in branch length, the fitting line between the beginning diameter and the end diameter is at a certain angle, indicating that the fruit branch of Lycium barbarum has a cone angle which varies with the branch length in a small range. In order to further reduce the model variables, the functions of taper angle and branch length are introduced to represent the end diameter. Branch length and Formula (1) can therefore be used to calculate the base diameter and top diameter of the branches as follows:

$$
\left\{\begin{array}{l}
D=0.0032 l+2.6151 \\
\theta=-0.000005 * l+0.0082 \\
d=\theta l
\end{array}\right.
$$

where, $D$ represents the diameter of the base circle of the branch, $d$ represents the diameter of the top circle of the branch, and $l$ represents the length of the fruiting branch, while $\theta$ represents the tangent of the taper angle.

Growth angle $\alpha$ represents the included angle between the branch growth direction and the superior branch growth direction, as shown in Figure 2a,c. The growth angle range of fruiting branches is shown in Table 3 , and the data were obtained through field measurement.

Table 3. Length, growth angle, and diameter of branches.

\begin{tabular}{ccccccccc}
\hline \multirow{2}{*}{ Type of Branches } & \multicolumn{2}{c}{ Length/mm } & \multicolumn{2}{c}{$\begin{array}{c}\text { Diameter at the Base } \\
\text { Circle/mm }\end{array}$} & \multicolumn{2}{c}{$\begin{array}{c}\text { Diameter at the Top } \\
\text { Circle/mm }\end{array}$} & $\begin{array}{c}\text { Growth } \\
\text { Angle/ }\end{array}$ & $\begin{array}{c}\text { Number of } \\
\text { Branches }\end{array}$ \\
\cline { 2 - 9 } & Range & $\begin{array}{c}\text { Annual } \\
\text { Growth }\end{array}$ & Range & $\begin{array}{c}\text { Annual } \\
\text { Growth }\end{array}$ & Range & $\begin{array}{c}\text { Annual } \\
\text { Growth }\end{array}$ & \\
\hline Fruiting branches & $310-1000$ & 314 & $1.7-3.4$ & 1.7 & $0.8-2.1$ & 1.7 & $40-87$ & $45-97$ \\
\hline
\end{tabular}

The quality of 100 randomly selected leaves, ripe fruits, unripe fruits, flowers, and fruit stalks was measured, as shown in Table 4.

Table 4. The quantity and quality of ripe fruits, leaves, green fruits, flowers, and fruit stalks growing on the nodes.

\begin{tabular}{ccccccccc}
\hline & \multicolumn{4}{c}{ Mass/g } & \multicolumn{3}{c}{ Nodes } \\
\cline { 2 - 9 } & $\begin{array}{c}\text { Maximum } \\
\text { Value }\end{array}$ & $\begin{array}{c}\text { Minimum } \\
\text { Value }\end{array}$ & $\begin{array}{c}\text { Average } \\
\text { Value }\end{array}$ & $\begin{array}{c}\text { Standard } \\
\text { Deviation }\end{array}$ & $\begin{array}{c}\text { Maximum } \\
\text { Value }\end{array}$ & $\begin{array}{c}\text { Minimum } \\
\text { Value }\end{array}$ & $\begin{array}{c}\text { Average } \\
\text { Value }\end{array}$ & $\begin{array}{c}\text { Standard } \\
\text { Deviation }\end{array}$ \\
\hline $\begin{array}{c}\text { Ripe fruit } \\
\text { Leaves }\end{array}$ & 1.240 & 0.320 & 0.812 & 0.192 & 6 & 2 & 3.21 & 0.217 \\
Unripe & 0.155 & 0.074 & 0.121 & 0.023 & 4 & 2 & 2.57 & 0.132 \\
fruit & 0.346 & 0.056 & 0.157 & 0.065 & 4 & 0 & 1.95 & 0.046 \\
Flowers & 0.110 & 0.020 & 0.055 & 0.019 & 6 & 0 & 3.41 & 0.017 \\
Stalks & 1.069 & 0.867 & 0.978 & 0.048 & 7 & 2 & 4.17 & 0.219 \\
\hline
\end{tabular}

\subsection{Deformation of Branches under Different Loads}

The deformation process of fruit-bearing L. barbarum branches under different loads is shown in Figure 7. Figure 7a shows that the branch grows upward along the growth angle, with only a small deformation. Figure $7 \mathrm{~b}-\mathrm{d}$ show the deformation process of the fruitbearing branches from the beginning of the fruit ripening to the full production stage. In this process, the bending degree of branches gradually increases, and the growth direction changes from oblique upward growth to ground growth. There are two main reasons for this. On the one hand, due to the long force arm at the end of the branch, the load increases, and the torque increases as the fruit at the end of the branch matures. On the other hand, the end of the branch is growing, the branch is thin, and the degree of lignification is low, making the end-bending effect more pronounced. In Figure 7e, the branch load was added. 
When the length of fruit-bearing branches exceeds $300 \mathrm{~mm}$, the thorns at some nodes will continue to grow and develop into the next level of fruit-bearing branches. These new branches are composed of newly germinating leaves, and green fruits will be born at the node. The branch length in the simulation is $500 \mathrm{~mm}$, and two lower-branch loads are applied. The application of a lower-branch load makes the branch reach the final shape of bending.

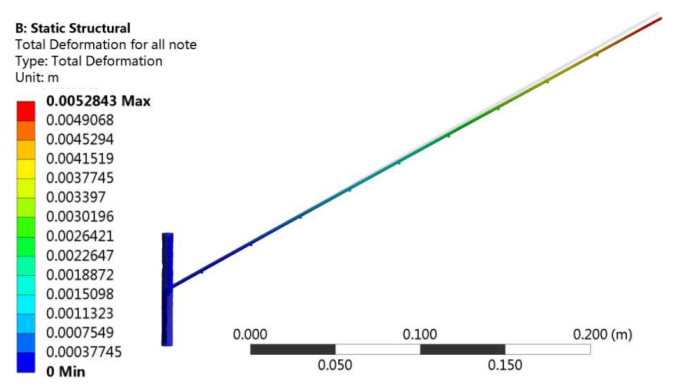

(a)

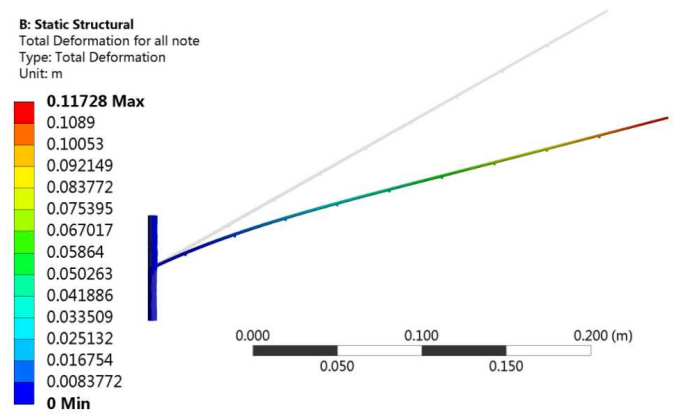

(c)

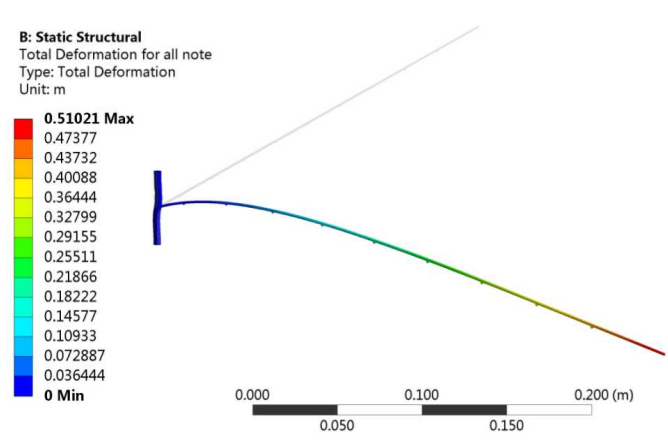

(e)

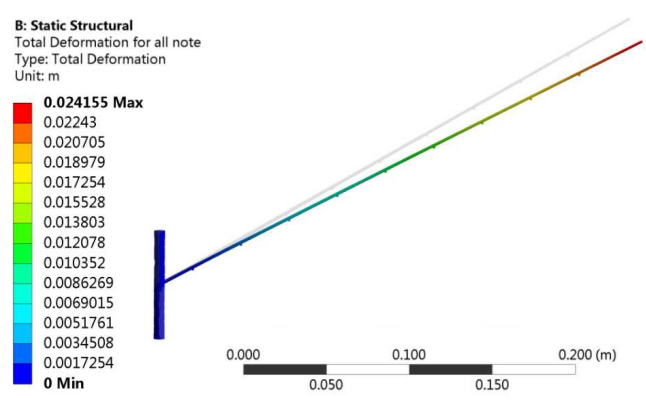

(b)

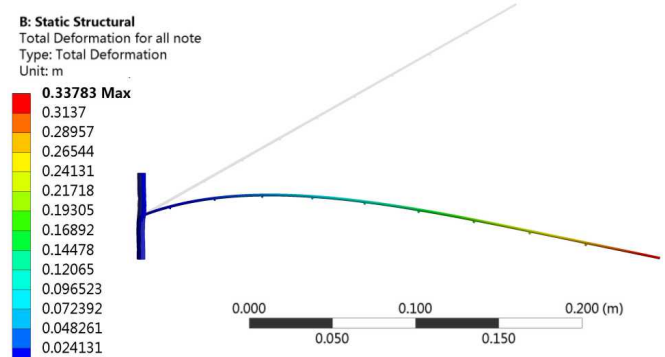

(d)

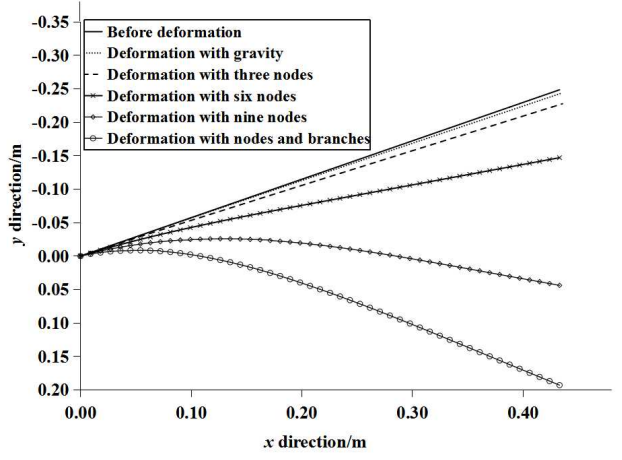

(f)

Figure 7. Deformation of fruit-bearing branches under different loads: (a) deformation under only branch gravity; (b) deformation under the action of the first three nodes; (c) deformation under the action of six nodes; (d) deformation when all nodes are loaded; (e) deformation with two branches; (f) comparison of centerline under each load deformation.

Using ANSYS post-processing, the coordinate values of 50 points on the branch centerline before and after deformation are obtained, and the shape curve of the branch before and after deformation is drawn, as shown in Figure 7f. The figure shows that for a $500 \mathrm{~mm}$ branch without load, under a load of fruit, leaves, and branches, the branch becomes slenderer, the growth direction changes from oblique upward growth to oblique downward growth, and the vertical height of the end of the branch reaches $441 \mathrm{~mm}$. 
Table 5 provides the contribution rates of different loads to branch deformation. The contribution rates of tip node and branch loads were the largest, with $43.22 \%$ and $33.79 \%$, respectively.

Table 5. Result of simulation.

\begin{tabular}{|c|c|c|c|c|c|c|}
\hline & Loads & Branch Gravity & 3 Nodes & 6 Nodes & 9 Nodes & Lower Branch \\
\hline \multirow{5}{*}{$\mathrm{x} / \mathrm{mm}$} & Before deformation & 433 & 433 & 433 & 433 & 433 \\
\hline & After deformation & 436 & 445 & 491 & 601 & 687 \\
\hline & Deformation & 3 & 9 & 46 & 110 & 86 \\
\hline & $\begin{array}{l}\text { Cumulative } \\
\text { deformation }\end{array}$ & 3 & 12 & 58 & 168 & 254 \\
\hline & Percentage & $1.04 \%$ & $3.70 \%$ & $18.26 \%$ & $43.21 \%$ & $33.80 \%$ \\
\hline \multirow{5}{*}{$\mathrm{Y} / \mathrm{mm}$} & Before deformation & -249 & -249 & -249 & -249 & -249 \\
\hline & After deformation & -244 & -228 & -147 & 44 & 193 \\
\hline & Deformation & 5 & 16 & 81 & 191 & 149 \\
\hline & $\begin{array}{l}\text { Cumulative } \\
\text { deformation }\end{array}$ & 5 & 21 & 101 & 292 & 441 \\
\hline & Percentage & $1.04 \%$ & $3.70 \%$ & $18.25 \%$ & $43.22 \%$ & $33.79 \%$ \\
\hline
\end{tabular}

Quadratic or cubic curves can describe Figure 7f, the curved shape of fruit-bearing branches, and the fitting equation of the branch shape is as follows:

$$
\begin{gathered}
y_{1}=0.9781 x^{2}+0.0743 x-0.0132\left(R^{2}=0.9946\right) \\
y_{2}=-2.9208 x^{3}+2.8752 x^{2}-0.2509 x-0.0021\left(R^{2}=0.9999\right)
\end{gathered}
$$

Equation (8) is a quadratic fitting curve, and Equation (9) is a cubic fitting curve. The $R^{2}$ values show that both methods can fit the branch shape. To determine the relationship between the parameters of the morphological equation and the fruit-bearing branch length, growth angle, and growth position, it is necessary to analyze the Box-Behnken test further.

\subsection{Relationship between Fruiting Branch Parameters and Branch Shape Equation Parameters}

Table 6 shows that both morphological curves predict the shape of branches. However, the $R^{2}$ value of the cubic curve is closer to 1 , so the prediction effect is better. If the parameters describing the shape curve of fruit-bearing branches can be determined by the parameters of branch length, growth angle, and growth position, rather than through simulation calculation every time, the drawing efficiency of fruit-bearing branches will be greatly improved. The relationship between each factor and each parameter of the cubic curve is analyzed visually and by variance. The analysis results are shown in Table 7 . The range analysis shows that the branch length had the most significant influence on the parameters $a_{1}$ and $a_{2}$, with a range $(R)$ of 2.1298 and 0.8612 . The branch growth angle has the greatest influence on parameter $a_{3}$, while the branch growth position has the greatest influence on parameter $a_{4}$. Analysis of variance shows that branch length had a significant effect on $a_{1}$. The growth angle significantly affects parameter $a_{3}$. 
Table 6. Simulation results of Box-Behnken test.

\begin{tabular}{cccccccccc}
\hline \multirow{2}{*}{$\begin{array}{c}\text { Test } \\
\text { No. }\end{array}$} & \multicolumn{9}{c}{ Cubic Curve } \\
\cline { 2 - 11 } & $\mathbf{a}_{\mathbf{1}}$ & $\mathbf{a}_{\mathbf{2}}$ & $\mathbf{\mathbf { a } _ { 3 }}$ & $\mathbf{a}_{\mathbf{4}}$ & $\boldsymbol{R}^{\mathbf{2}}$ & $\mathbf{b}_{\mathbf{1}}$ & $\mathbf{b}_{\mathbf{2}}$ & $\mathbf{b}_{\mathbf{3}}$ & $\boldsymbol{R}^{\mathbf{2}}$ \\
\hline 1 & -3.5772 & 1.6055 & -1.1306 & -0.0005 & 1.0000 & 0.4525 & -1.0346 & -0.0019 & 0.9998 \\
2 & -2.635 & 2.6223 & -0.2378 & 0.0034 & 0.9998 & 1.275 & -0.0566 & -0.0014 & 0.997 \\
3 & -1.3218 & 0.8902 & -0.5767 & -0.0001 & 1.0000 & 0.342 & -0.5168 & -0.0014 & 0.9997 \\
4 & -2.7624 & 2.5061 & -0.0279 & 0.0043 & 1.0000 & 1.1941 & 0.1371 & 0.0001 & 0.9987 \\
5 & -1.2636 & 1.9301 & -1.1905 & -0.0003 & 1.0000 & 0.9566 & -0.9959 & -0.0078 & 0.998 \\
6 & -0.8666 & 1.3506 & -0.6116 & 0.0002 & 0.9995 & 0.5403 & -0.4139 & -0.0092 & 0.9625 \\
7 & -0.9497 & 1.5631 & -0.5054 & -0.0018 & 0.9994 & 0.6195 & -0.2645 & -0.0129 & 0.9715 \\
8 & -0.9497 & 1.5631 & -0.5054 & -0.0018 & 0.9994 & 0.6195 & -0.2645 & -0.0129 & 0.9715 \\
9 & -0.9497 & 1.5631 & -0.5054 & -0.0018 & 0.9994 & 0.6195 & -0.2645 & -0.0129 & 0.9715 \\
10 & -0.0131 & 0.033 & -0.4192 & -0.0002 & 1.0000 & 0.0229 & -0.4172 & -0.0003 & 1.0000 \\
11 & -0.0131 & 0.0329 & -0.4192 & -0.0002 & 1.0000 & 0.0229 & -0.4172 & -0.0003 & 1.0000 \\
12 & -0.4578 & 1.1095 & -0.2222 & 0.0012 & 0.9999 & 0.7086 & -0.1299 & -0.003 & 0.9986 \\
13 & -0.1345 & 0.258 & -0.1391 & -0.0002 & 0.9999 & 0.1461 & -0.1145 & -0.0013 & 0.9950 \\
14 & -0.5552 & 1.2695 & -0.9245 & -0.0088 & 0.9978 & 0.4701 & -0.6284 & -0.0292 & 0.9718 \\
15 & -0.3598 & 1.0092 & -0.5665 & -0.0004 & 1.0000 & 0.5062 & -0.3862 & -0.0122 & 0.9774 \\
16 & -0.5337 & 1.3275 & -0.1867 & 0.0017 & 1.0000 & 0.5502 & 0.11 & -0.0207 & 0.9972 \\
17 & -0.3285 & 1.0178 & -0.113 & 0.0033 & 0.9999 & 0.6042 & 0.0242 & 0.0058 & 0.9991 \\
\hline
\end{tabular}

Table 7. Results of range and variance analysis of shape parameters.

\begin{tabular}{|c|c|c|c|c|c|c|c|c|c|c|c|c|}
\hline \multirow{2}{*}{$\begin{array}{c}\text { Factors } \\
\begin{array}{c}\text { Morphological } \\
\text { Parameters }\end{array}\end{array}$} & \multicolumn{4}{|c|}{ A } & \multicolumn{4}{|c|}{ B } & \multicolumn{4}{|c|}{$\mathrm{C}$} \\
\hline & $a_{1}$ & $a_{2}$ & $a_{3}$ & $a_{4}$ & $a_{1}$ & $a_{2}$ & $a_{3}$ & $\mathbf{a}_{4}$ & $a_{1}$ & $\mathbf{a}_{2}$ & $a_{3}$ & $\mathbf{a}_{4}$ \\
\hline Range (R) & 2.1298 & 0.8612 & 0.0543 & 0.0028 & 0.7073 & 0.3607 & 0.8388 & 0.0045 & 0.617 & 0.6154 & 0.4694 & 0.0047 \\
\hline$p$-value & 0.005 & 0.3016 & 0.9808 & 0.5126 & 0.6823 & 0.8279 & 0.002 & 0.2183 & 0.9027 & 0.8009 & 0.2147 & 0.1371 \\
\hline
\end{tabular}

Figure 8 shows the changing trend between each variable and the morphological parameters. With the increase in branch length from $300 \mathrm{~mm}$ to $800 \mathrm{~mm}$, the shape parameter $a_{1}$ first increases and then decreases. The shape parameter $a_{2}$ reaches the maximum when the branch length is $300 \mathrm{~mm}$, decreases gradually, and increases gradually when the branch length exceeds $600 \mathrm{~mm}$. The coefficients $a_{3}$ and $a_{4}$ increased monotonically with the increase in branch length. The shape parameters $a_{1}$ and $a_{2}$ did not change significantly with the growth angle. The shape parameters $a_{3}$ and $a_{4}$ gradually increased with the growth angle by $38 \%$ and $50 \%$, respectively.

Design-expert 8.0.6 (Stat-Ease, Inc., Minneapolis, MN, USA) directly calculates the regression model with each shape parameter as the response function and each factor as the independent variable. The $p$-values of the $\mathrm{a}_{1}, \mathrm{a}_{2}$, and $\mathrm{a}_{3}$ prediction models are $0.0001,0.0067$, and 0.0203 , respectively, indicating that the regression model is statistically significant. The value of parameter $\mathrm{a}_{4}$ in each process is less than 0.01 , so the average value of each process -0.00012 can be used in the final prediction model. The final expression of the prediction model is shown in Formula (10):

$$
\left\{\begin{array}{l}
y^{3}=\mathrm{a}_{1} \mathrm{x}^{3}+\mathrm{a}_{2} \mathrm{x}^{2}+\mathrm{a}_{3} \mathrm{x}-0.00012 \\
\mathrm{a}_{1}=-16.92676+0.03218 A+0.31355 B-1.88578 C-0.00012 A B-0.00002 A^{2}-0.00194 B^{2}+0.39538 C^{2} \\
\mathrm{a}_{2}=8.11901-0.01307 A-0.06238 B-1.41951 C+0.02218 B C+0.00001 A^{2} \\
\mathrm{a}_{3}=-2.57623+4.81457 A+0.00512 B+0.11411 C-0.000003 A^{2} \\
\mathrm{a}_{4}=-0.00012
\end{array}\right.
$$




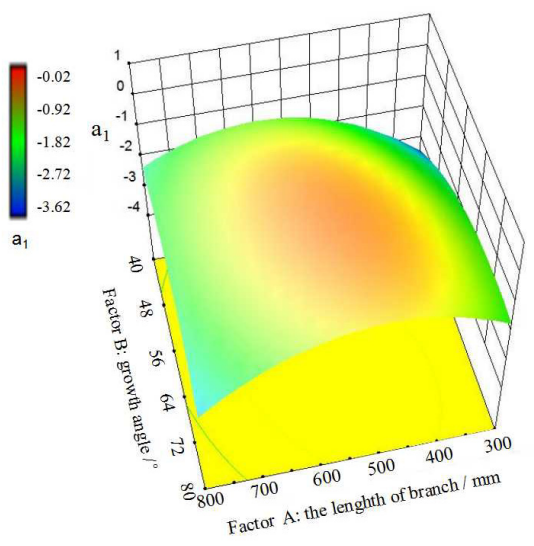

(a)

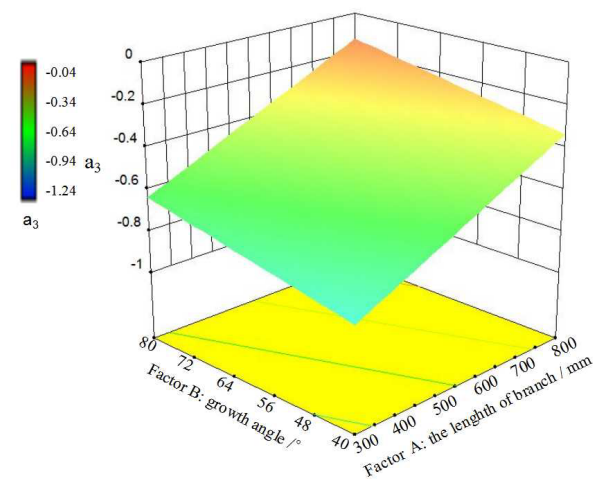

(c)

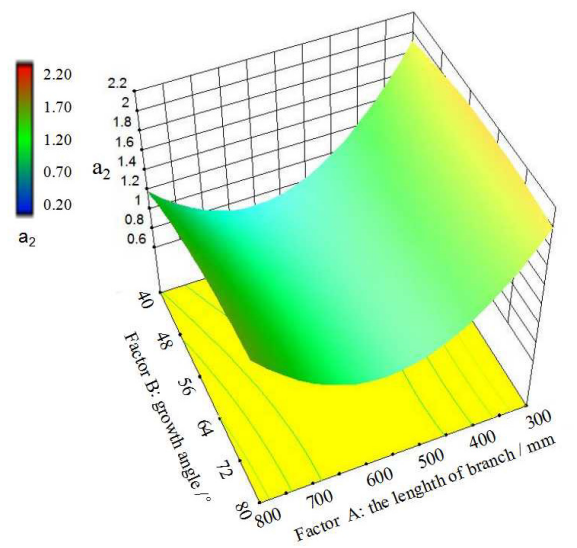

(b)

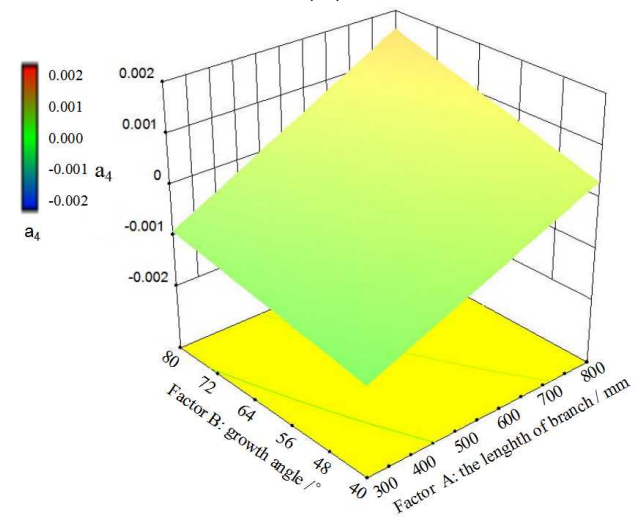

(d)

Figure 8. Response surface of various parameters of the cubic morphological equation to each factor: (a) effects of branch length and growth angle on parameter $\mathrm{a}_{1} ;(\mathbf{b})$ effects of branch length and growth angle on parameter $\mathrm{a}_{2} ;$ (c) effects of branch length and growth angle on parameter $\mathrm{a}_{3} ;(\mathbf{d})$ effects of branch length and growth angle on parameter $\mathrm{a}_{4}$.

\subsection{Error Analysis of Branch Shape Prediction Model}

Figure $9 a-d$ show the front image and image processing of the branches. Figure $9 a$ is the original picture. After manually removing the non-target area, Figure $9 \mathrm{~b}$ is obtained. Figure $9 \mathrm{~b}$ is transformed into a gray image, and threshold segmentation is carried out to obtain the binary in Figure 9c. From the enlarged picture, there are many burrs on the edge of the branch, which will increase the error in the subsequent coordinate picking. A morphological closed operation corrodes the branches to obtain a relatively smooth binary, as shown in Figure 9d. Figure 9e is the scatter diagram of the branches in the pixel coordinate system. To obtain the coordinate value of the branch centerline, it is necessary to take the average value of multiple $y$ values corresponding to the $x$ value of each pixel coordinate. However, the rotation on the left side of the branch overlaps the $x$ coordinates. Therefore, the picture is divided into left and right at pixel abscissa 640, as shown by the red line in Figure 9e. The mean value of multiple $x$ values corresponding to the $y$ value is calculated in the left half of the picture to determine the actual coordinate values of 50 points equidistant from the centerlines of the left and right branches, respectively. 


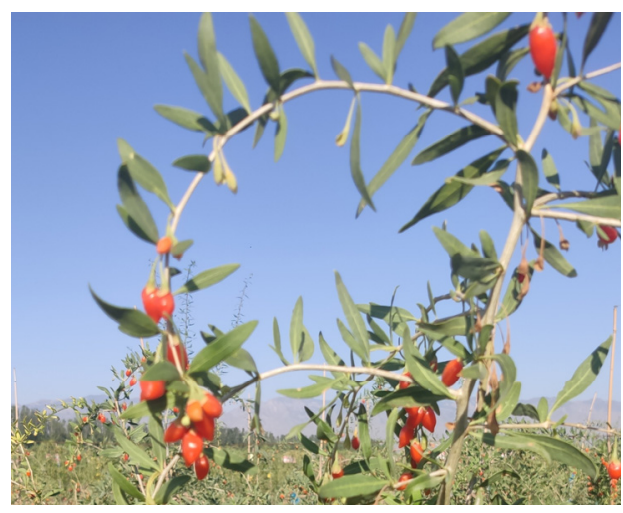

(a)

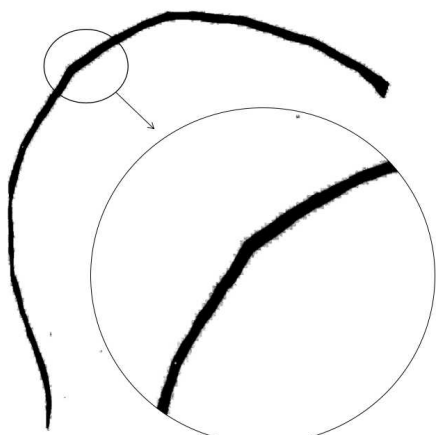

(c)

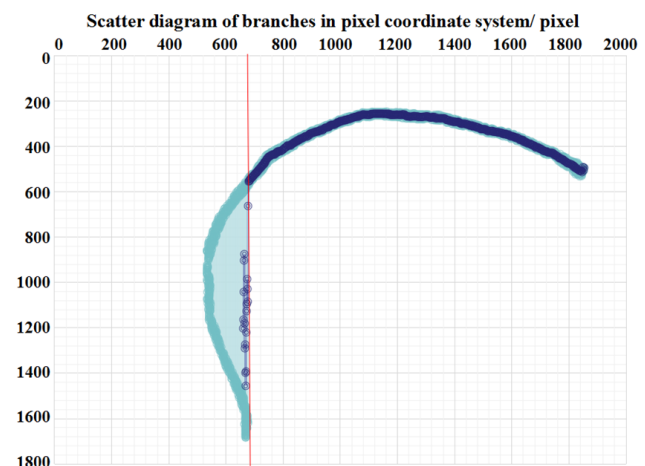

(e)

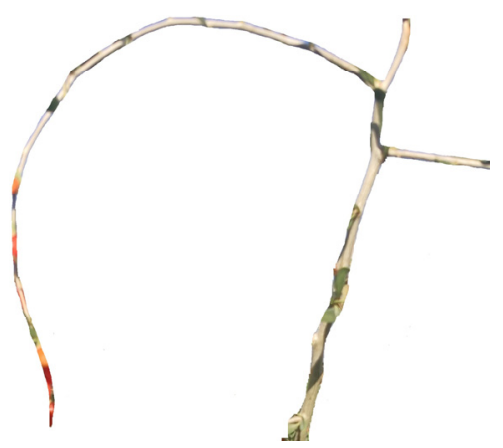

(b)

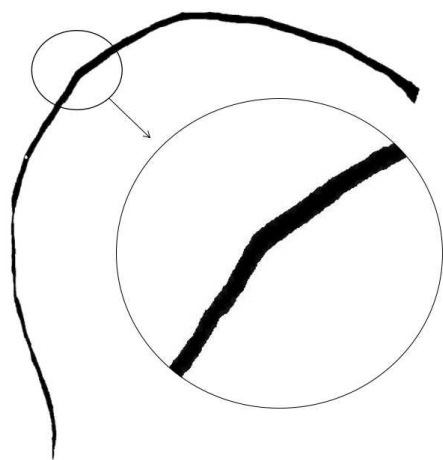

(d)

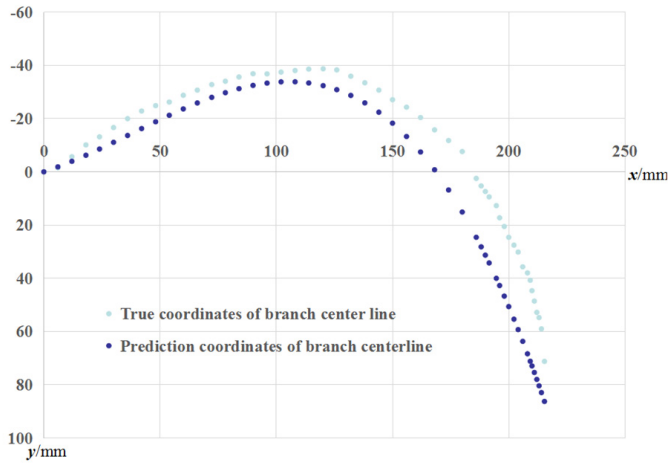

(f)

Figure 9. Image processing of branches: (a) original image; (b) manually remove the target area; (c) binary diagram; (d) morphological operation; (e) scatter diagram of 50 points on the branch centerline in the picture pixel coordinate system; (f) scatter diagram of 50 points on the centerline of real branches and predicted branches in the branch coordinate system.

The branch length is $492.4 \mathrm{~mm}$, the growth angle is $74.8^{\circ}$, and the growth position is 3 . The branch shape curve parameters $a_{1}, a_{2}$, and $a_{3}$, are $0.000032,-0.00369$, and -0.28750 , respectively. The three parameters are incorporated into Formula (10) to calculate the predicted coordinate values of 50 points on the branch centerline. The scatter diagram of predicted coordinates and real coordinates in the length coordinate system is shown in Figure $9 \mathrm{f}$.

Table 8 shows the actual value $y_{t}$, predicted value $y_{p}$, and relative error of the coordinates of 50 points on the branch centerline. Figure $9 f$ shows that the prediction curve simulates the shape of branches growing upward first and then bending downward by gravity. Among the 50 points, 16 points had a relative error of less than $5 \%$ of the predicted value, 18 points were between $5-20 \%$, and the relative error of 16 points was higher than $20 \%$. 
Table 8. Real value, predicted value, and relative error of coordinates of each point on the middle line of fruit-bearing branch.

\begin{tabular}{|c|c|c|c|c|c|c|c|c|c|}
\hline No. & $\mathrm{x} / \mathrm{mm}$ & $\mathrm{y}_{\mathrm{t}} / \mathrm{mm}$ & $\mathrm{y}_{\mathrm{p}} / \mathrm{mm}$ & Relative Error & No. & $\mathrm{x} / \mathrm{mm}$ & $\mathrm{y}_{\mathrm{t}} / \mathrm{mm}$ & $\mathrm{y}_{\mathrm{p}} / \mathrm{mm}$ & Relative Error \\
\hline 1 & 0.00 & 0.00 & 0.00 & $0.00 \%$ & 26 & 149.95 & -27.10 & -18.27 & $8.03 \%$ \\
\hline 2 & 6.03 & -1.50 & -1.86 & $0.33 \%$ & 27 & 155.98 & -24.29 & -13.27 & $10.02 \%$ \\
\hline 3 & 12.06 & -5.67 & -3.94 & $1.57 \%$ & 28 & 162.01 & -20.40 & -7.45 & $11.78 \%$ \\
\hline 4 & 18.09 & -10.11 & -6.22 & $3.54 \%$ & 29 & 168.04 & -15.77 & -0.76 & $13.65 \%$ \\
\hline 5 & 23.96 & -13.14 & -8.56 & $4.17 \%$ & 30 & 174.07 & -11.76 & 6.81 & $16.89 \%$ \\
\hline 6 & 29.99 & -16.63 & -11.08 & $5.05 \%$ & 31 & 179.94 & -7.61 & 15.10 & $20.66 \%$ \\
\hline 7 & 36.02 & -19.97 & -13.65 & $5.75 \%$ & 32 & 185.97 & 2.48 & 24.60 & $20.12 \%$ \\
\hline 8 & 42.05 & -22.84 & -16.24 & $6.00 \%$ & 33 & 188.09 & 5.30 & 28.18 & $20.81 \%$ \\
\hline 9 & 48.08 & -24.87 & -18.80 & $5.52 \%$ & 34 & 189.88 & 7.40 & 31.31 & $21.75 \%$ \\
\hline 10 & 53.95 & -26.21 & -21.23 & $4.53 \%$ & 35 & 191.51 & 9.41 & 34.23 & $22.58 \%$ \\
\hline 11 & 59.98 & -28.75 & -23.62 & $4.67 \%$ & 36 & 194.61 & 12.71 & 40.01 & $24.83 \%$ \\
\hline 12 & 66.01 & -30.69 & -25.86 & $4.39 \%$ & 37 & 196.02 & 17.28 & 42.72 & $23.14 \%$ \\
\hline 13 & 72.20 & -32.78 & -27.97 & $4.38 \%$ & 38 & 198.02 & 20.54 & 46.70 & $23.79 \%$ \\
\hline 14 & 78.07 & -34.02 & -29.73 & $3.90 \%$ & 39 & 199.94 & 24.61 & 50.63 & $23.67 \%$ \\
\hline 15 & 83.94 & -35.63 & -31.23 & $4.00 \%$ & 40 & 202.19 & 27.55 & 55.37 & $25.30 \%$ \\
\hline 16 & 89.97 & -36.86 & -32.46 & $4.00 \%$ & 41 & 203.99 & 30.15 & 59.28 & $26.50 \%$ \\
\hline 17 & 96.00 & -36.80 & -33.33 & $3.16 \%$ & 42 & 205.96 & 35.69 & 63.69 & $25.47 \%$ \\
\hline 18 & 102.03 & -37.46 & -33.79 & $3.34 \%$ & 43 & 208.00 & 37.98 & 68.36 & $27.63 \%$ \\
\hline 19 & 108.06 & -38.05 & -33.82 & $3.85 \%$ & 44 & 209.20 & 40.75 & 71.17 & $27.67 \%$ \\
\hline 20 & 113.93 & -38.59 & -33.37 & $4.75 \%$ & 45 & 209.93 & 44.66 & 72.92 & $25.70 \%$ \\
\hline 21 & 120.12 & -38.71 & -32.36 & $5.78 \%$ & 46 & 210.96 & 48.57 & 75.39 & $24.40 \%$ \\
\hline 22 & 125.99 & -38.28 & -30.85 & $6.76 \%$ & 47 & 212.02 & 52.81 & 77.99 & $22.90 \%$ \\
\hline 23 & 132.02 & -35.91 & -28.70 & $6.56 \%$ & 48 & 212.99 & 54.76 & 80.39 & $23.31 \%$ \\
\hline 24 & 138.05 & -33.46 & -25.89 & $6.89 \%$ & 49 & 214.01 & 59.00 & 82.94 & $21.78 \%$ \\
\hline 25 & 144.08 & -30.70 & -22.38 & $7.57 \%$ & 50 & 215.31 & 71.23 & 86.27 & $13.68 \%$ \\
\hline
\end{tabular}

\section{Discussion}

The fruiting branches begin to sprout and grow in April each year. With branch length and diameter growth, the leaves and fruits on each node of the fruit-bearing branches gradually develop and grow. In this process, the branch load gradually increases, their lignification degree gradually increases, and their shape gradually bends, which is irreversible. Therefore, the branches reached the final bending shape at the full fruit stage with the maximum load. In mid-June, the fruit on the upper end of the fruiting branch develops and ripens first, followed by the fruit in the middle of the branch, and finally by the fruit at the end of the branch. This also explains why the fruit begins to mature from the root of L. barbarum branches. The lignification of fruit branches is a gradual process. Compared with the apical fruits, root fruits are less likely to maintain the stability of the L. barbarum plant system due to the shorter force arms and less load on the branch system when they mature. Although the load increases significantly when the terminal fruit is mature, the plant system is developed enough to maintain its stability with the gradual lignification of fruit-bearing branches. In order to study the damage to broad-leaved trees caused by wind load, the deformation model of trees under the action of gravity was also established in [34]. In that study, the tree data were first obtained by ground lidar, and the tree model was reconstructed. Then the anti-gravity load was applied to the trees to obtain the plant model without gravity. The study shows that the effect of gravity load on the deformation of branches is a cumulative effect. This is similar to the results of this paper.

In order to verify the accuracy of the model, it is necessary to establish a plane coordinate system for the actual branches which is exactly the same as the simulation calculation. However, the actual coordinates of each point on the axis of the actual branch are difficult to obtain by measurement. This is due to the fact that the shape of the actual branch is three-dimensional, and there is a sudden change in the diameter of the branch node. The branches have unsmooth bending to obtain more light. The error of points no. 41,43 , and 44 exceeds $25 \%$, which may be caused by pruning or spatial competition among 
branches. Catherine Jirasek pointed out in [35] that, under natural conditions, the bending of branches is sagged by their load, and also affected by phototaxis, artificial pruning, and lateral wind, and therefore making calculations is very complex.

The modeling of Lycium barbarum was also studied in [1]. In order to ensure that more ripe fruit and less green fruit is obtained during the harvest process, simulation experiments and field experiments on the shedding sequence of fruit and fruit stalks from branches under tension were carried out. In [1], the fruit-pedicel-stalk-branch system was constructed by reverse engineering. The reverse engineering method constructs the three-dimensional model completely according to the real object, and the model accuracy is therefore high, which provides a reliable geometric model for simulation analysis. However, the reverse engineering method is completely based on physical creation, and the flexibility of the model is poor. Reverse engineering with the help of 3D scanning methods for reconstruction requires the creation of the complex branch structure of the whole plant (including thousands of leaves and dozens of hanging fruit branches), or even different branch types of multiple plants. The modeling process is not efficient enough to meet these needs. In this study, the parameters that determine the branch shape (length, growth angle, and growth mode) can obtain from the actual branches, or can be randomly determined by the research needs within a reasonable range. After these three parameters are determined, the branches in accordance with the growth law can be obtained by the branch shape prediction model. It should be pointed out that the branch morphology predicted in this study is one of the actual growth forms of branches. This is because the branches with the same length, growth angle and growth position will have some differences in growth morphology when affected by water stress, nutrient competition among branches, accumulated temperature during the growth period, and so on. In order to study the power transfer characteristics of Lycium barbarum plants, the three-dimensional model of Lycium barbarum plants was established by measurement, and the decreasing characteristics of power among all levels of branches were determined in [31]. In this study, because of the large number of hanging fruit branches and the difficulties of measuring the bending shape, the three-dimensional model does not include hanging fruit branches in order to facilitate the analysis, and the study does not include the dynamic transfer characteristics from hanging fruit branches to the Lycium barbarum fruit. The actual measurement can truly reflect the geometric shape of specific plants, but the complex bending shape of fruit branches and the large number of fruit branches bring difficulties to the measurement.

Since 1959 [36], researchers have tried to calculate the geometric shape and internal stress of branches under gravity and ecological constraints by means of mechanical analysis. Fournier obtained a semi-analytical solution [37], and Fourcaud developed a numerical finite element model $[25,26]$ to adjust the branch shape. The above methods focus on establishing the mechanical equation and solving the equation to generate the geometric shape of the branch. However, after the branch parameters are given, they still need finite element calculation to obtain the branch shape. In a 2014 study [38], Guillaume reconstructed the biomechanical model of branches considering the effect of progressive maturity on branch morphology. These studies aim to explore the mechanism of branch morphological development and establish the mechanical model of plant morphology. In our study, the progressive, mature finite element calculation is considered to ensure the accuracy of the model prediction, and the prediction equation is determined by orthogonal simulation experiments to ensure the rapidity of modeling. Therefore, we can flexibly and quickly create a three-dimensional model of the hanging fruit branch.

The efficient establishment of a branch bending model is helpful to further study the harvesting mechanism of Chinese wolfberries and improve the development efficiency of Chinese wolfberry harvesters. It can be seen from references $[1,31]$ that due to the limited accuracy and efficiency of branch bending modeling, some studies are carried out only on a single fruit branch, while others directly ignore the role of fruit branch, which reduces the generality and reliability of the research results. By carrying out simulation research on the basis of this study, we can quickly obtain a large number of shapes of 
fruit-hanging branches in accordance with mechanical law so as to quickly establish the three-dimensional model of fruit-hanging branches. In the analysis of vibration harvesting mechanisms, fruit branches with different lengths and branch angles can be created flexibly, and the finite element method can be used to solve the vibration response of branches. In the simulation analysis of airwave picking, we can create a single fruit branch or multiple fruit branches growing in various ways, so as to study the effect of different air flows. In the simulation research process of medlar pruning and pesticide application, the crown shape or application position of the rich fruit branches can be more intuitively viewed.

The next step of this study is to construct the whole plant model, and explore the dynamic response of leaves and fruits under the action of contact force and air flow. On the other hand, it is necessary to introduce more influencing factors in the construction of the plant model to improve the openness of the prediction model and incorporate different Chinese wolfberry varieties and berries to expand the application of the model according to their own cultivation characteristics.

\section{Conclusions}

The prediction model of fruit-bearing branch bending of L. barbarum was obtained through the finite element simulation test of branches. The experimental analysis shows that the prediction result of the cubic model is better than the quadratic model. The length of branches has a significant impact on the cubic and quadratic term coefficients of the prediction model, the growth angle of branches has a significant impact on the primary phase coefficient of the prediction model, and the constant term of the prediction model of different fruit-bearing branches has little change. The growth position of branches had no significant effect on the bending shape of branches.

The large deformation and sagging of fruit-bearing branches of L. barbarum is mainly caused by the loads of mature fruits and lower branches. Therefore, the longer the branch, the more nodes on the branch, the more fruits and branches growing on the branch, and the greater the bending deformation of the branch. The bending of fruit-bearing branches is an irreversible process of gradual development, and the branches reach the final shape in the full production stage. The fruit ripening sequence on the fruit-bearing branch is conducive to protecting the stability of the plant structure.

The branch shape prediction model better simulates the branch shape, but the coordinate error of the corresponding points is still large. Adding more factors, such as the phototaxis of branches, artificial pruning, and nutritional competition between branches, into the model to obtain a more accurate prediction model is the next step for this research.

Author Contributions: Conceptualization, Y.C. and J.C.; methodology, Y.C., J.Z., Q.C. and J.C.; software, Y.C.; validation, Y.C.; investigation, Y.C., J.Z. and Q.C.; writing-original draft preparation, Y.C.; writing-review and editing, Y.C. and J.C.; visualization, Y.C. and J.C.; funding acquisition, J.C. All authors have read and agreed to the published version of the manuscript.

Funding: This research and APC were funded by the National Key Research and Development Program of China, grant number 2018YFD0701102.

Institutional Review Board Statement: Not applicable.

Informed Consent Statement: Not applicable.

Data Availability Statement: Not applicable.

Conflicts of Interest: The authors declare no conflict of interest. 


\section{References}

1. Zhao, J.; Ma, T.; Inagaki, T.; Chen, Q.; Gao, Z.; Sun, L.; Cai, H.; Chen, C.; Li, C.; Zhang, S.; et al. Finite element method simulation and experiments of detachments of Lycium barbarum L. Forests 2021, 12, 699. [CrossRef]

2. Bu, L.; Hu, G.; Chen, C.; Sugirbay, A.; Chen, J. Experimental and simulation analysis of optimum picking patterns for robotic apple harvesting. Sci. Hortic. 2021, 261, 108937. [CrossRef]

3. Li, Z.; Lin, D.; Song, H.; Xu, Y. A fast leaf fall simulation method faithful to plant physiology. Inf. Technol. Netw. Secur. 2015, 13, 77-79. [CrossRef]

4. Ulam, S. On some mathematical properties connected with patterns of growth of figures. In Proceedings of the Symposia on Applied Mathematics; American Mathematical Society: Urbana, IL, USA, 1962; pp. 215-224.

5. Cohen, D. Computer simulation of biological pattern generation processes. Nature 1967, 216, 246-248. [CrossRef]

6. Aristed, L. Mathematical models for cellular interactions in development. I: Filaments with one-sided inputs. J. Theor. Biol. 1968, 18, 280-299. [CrossRef]

7. Aristed, L. Mathematical models for cellular interactions in development.II:Simple and branching filaments with two-sided inputs. J. Theor. Biol. 1968, 18, 300-315. [CrossRef]

8. Csuri, C.; Hackathorn, R.; Parent, R.; Carlson, W.; Howard, M. Toward an interactive high visual complexity animation system. ACM Siggraph Comput. Graph. 1979, 13, 289-299. [CrossRef]

9. James, F. Light reflection function for simulation of clouds and dusty surfaces. ACM Siggraph Comput. Graph. 1982, 16, 21-29. [CrossRef]

10. William, T. Particle systems-A technique for modeling a class of fuzzy objects. ACM Trans. Graph. 1983, 2, 91-108.

11. William, T.; Ricki, B. Approximate and probabilistic algorithms for shading and rending structured particle system. ACM Siggraph Comput. Graph. 1985, 19, 313-322. [CrossRef]

12. Reffye, P.; Cloude, E.; Jean, F.; Marc, J.; Cloude, P. Plant models faithful to botanical structure and development. ACM Siggraph Comput. Graph. 1988, 22, 151-158. [CrossRef]

13. Reffye, P.; Marc, J. Basic concepts of computer simulation of plant growth. J. Biosci. 1992, 17, $275-291$.

14. Reffye, P.; Fourcaud, T.; Blaise, F.; Barthelemy, D.; Houllier, F. A functional model of tree growth and tree architecture. Silva Fenn. 1997, 31, 297-311. [CrossRef]

15. Corina, I.; Paul, H.C.; Thomas, G.; Benoît, B.; Didier, B.; Matthieu, C. Model-based analysis synthesis for realistic tree reconstruction and growth simulation. IEEE Trans. Geosci. Remote Sens. 2014, 52, 1438-1450. [CrossRef]

16. Zhang, Y.; Yu, W.; Zhao, X.; Lyu, Y.; Feng, W.; Li, Z.; Hu, S. Interactive tree segmentation and modeling from ALS point clouds. J. Graph. 2021, 42, 599-607.

17. Mikio, S.; Alain, F. Stochastic motion-motion under the influence of wind. Comput. Graph. Forum 1992, 11, 119-128. [CrossRef]

18. Jos, S. Stochastic dynamics: Simulating the effects of turbulence on flexible structures. Comput. Graph. Forum 1997, 16, 159-164. [CrossRef]

19. Sakaguchi, T.; Ohya, J. Modeling and animation of botanical trees for interactive virtual environments. In Proceedings of the VRST'99 Symposium on Virtual Reality Software and Technology, London, UK, 20-22 December 1999; pp. 139-146. [CrossRef]

20. Hui, F.; Hohn, C. Randomly accessible procedural animation of physically approximate turbulent motion. In Proceedings of the Computer Animation (CA 2002), Geneva, Switzerland, 21 June 2002; pp. 43-48. [CrossRef]

21. Kondo, R.; Miyajima, S.; Ohide, T. Comparison of two accelerations for interactive animation of trees. In Proceedings of the Visualization, Imaging, and Image Processing (VIIP 2003), Benidorm, Spain, 7-9 September 2003; pp. 177-185.

22. Beaudoin, J.; Keyser, J. Simulation levels of detail for plant motion. In Proceedings of the SCA'04: Proceedings of the 2004 ACM SIGGRAPH, Grenoble, France, 27-29 August 2004; pp. 297-304. [CrossRef]

23. Jules, B. Modeling the mighty maple. Comput. Graph. 1985, 19, 305-311. [CrossRef]

24. Weber, J.; Penn, J. Creation and rendering of realistic trees. In Proceedings of the 22nd Annual Conference on Computer Graphics and Interactive Techniques, Los Angeles, CA, USA, 6-11 August 1995; pp. 119-128.

25. Fourcaud, T.; Blaise, F.; Lac, P.; Castera, P.; Reffye, P. Numerical modelling of shape regulation and growth stresses in trees I. an incremental static finite element formulation. Trees 2003, 17, 23-30. [CrossRef]

26. Fourcaud, T.; Blaise, F.; Lac, P.; Castera, P.; Reffye, P. Numerical modelling of shape regulation and growth stresses in trees II. Implementation in the AMAPpara software and simulation of tree growth. Trees 2003, 17, 31-39. [CrossRef]

27. Qin, G.; Wang, P. Lycium barbarum; China Science Publishing \& Media Ltd.: Beijing, China, 1978; pp. 18-20.

28. Zheng, G. The Studies of the Relationship between the Structure, Development and Sugar Accumulation in Fruits. Ph.D. Thesis, Northwest University, Xi'an, China, 2011.

29. Zhang, Z. The Design and Experiment of Lycium Barbarum Harvesting Mechanism by Vibration Mode. Master's Thesis, Chinese Academy of Agricultural Sciences, Beijing, China, 2016.

30. Hu, M.; Wang, F.; Dong, X.; He, X. Design of bibrating wolfberry picking machine. J. Chin. Agric. Mech. 2018, 39, 25-29. [CrossRef]

31. He, M.; Kan, Z.; Li, C.; Wang, L.; Yang, L.; Wang, Z. Mechanism analysis and experiment on vibration harvesting of wolfberry. Trans. CSAE 2017, 33, 47-53. [CrossRef]

32. He, B.; Tang, J.; Fan, Q. Derivation of beam deflection curve differential equation by direct definition method. Mech. Eng. 2009, 4, 80-81. [CrossRef] 
33. Chen, Y.; Wang, Y.; Zhao, J.; Chen, J. Recognition of the position of Chinese wolfberry branches under the artificial background. IFAC Pap. 2018, 51, 321-325. [CrossRef]

34. Jackson, T.; Shenkin, A.; Wellpott, A.; Calders, K.; Origo, N.; Disney, M. Finite element analysis of trees in the wind based on terrestrial laser scanning data. Agric. For. Meteorol. 2019, 265, 137-144. [CrossRef]

35. Catherine, J.; Przemyslaw, P.; Bruno, M. Integrating biomechanics into developmental plant models expressed using L-systems. In Proceedings of the 3rd Plant Biomechanics Conference, Freiburg-Badenweiler, Germany, 27 August-2 September 2000; pp. 615-624.

36. Kubler, H. Studies on growth stresses in trees. 1. The origin of growth stresses and the stresses in transverse direction. Holz Als Roh Werkst. 1959, 17, 1-9. Available online: http:/ /link.springer.com/content/pdf/10.1007\%2FBF02608827.pdf (accessed on 22 September 2021).

37. Fournier, M.; Chanson, B.; Thibaut, B.; Guitard, D. Mechanics of standing trees: Modelling a growing structure submitted to continuous and fluctuating loads. 1. Analysis of support stresses. Ann. For. Sci. 1991, 48, 513-525. [CrossRef]

38. Guillaume, P.; Catherine, C.; Evelyne, T.; Jean-Benoit, L.; Saudreau, M. A model to simulate the gravitropic responseand internal stresses in trees, considering the progressive maturation of wood. Trees-Struct. Funct. 2014, 28, 1235-1248. 